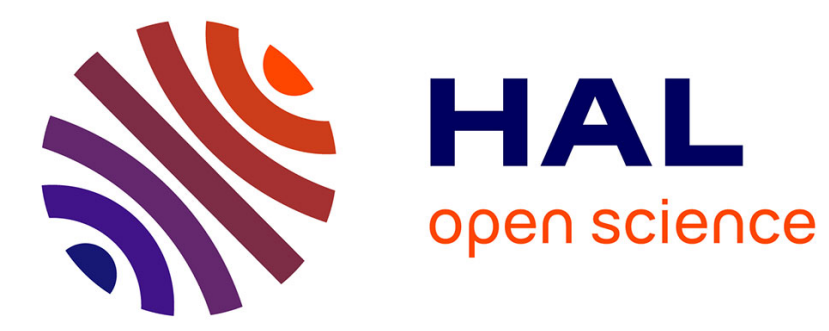

\title{
Probability maps of reservoir presence and sensitivity analysis in stratigraphic forward modeling
}

Véronique Gervais, Mathieu Ducros, Didier Granjeon

\section{To cite this version:}

Véronique Gervais, Mathieu Ducros, Didier Granjeon. Probability maps of reservoir presence and sensitivity analysis in stratigraphic forward modeling. AAPG Bulletin, 2018, 102 (04), pp.613 - 628. 10.1306/0913171611517242 . hal-01883765

\section{HAL Id: hal-01883765 \\ https://hal-ifp.archives-ouvertes.fr/hal-01883765}

Submitted on 28 Sep 2018

HAL is a multi-disciplinary open access archive for the deposit and dissemination of scientific research documents, whether they are published or not. The documents may come from teaching and research institutions in France or abroad, or from public or private research centers.
L'archive ouverte pluridisciplinaire HAL, est destinée au dépôt et à la diffusion de documents scientifiques de niveau recherche, publiés ou non, émanant des établissements d'enseignement et de recherche français ou étrangers, des laboratoires publics ou privés. 


\section{(3APG BULLETIN}

\section{Probability maps of reservoir presence and sensitivity analysis in stratigraphic forward modeling}

Véronique Gervais, Mathieu Ducros, and Didier Granjeon

AAPG Bulletin published online 08 November 2017

doi: 10.1306/0913171611517242

Disclaimer: The AAPG Bulletin Ahead of Print program provides readers with the earliest possible access to articles that have been peer-reviewed and accepted for publication. These articles have not been copyedited and are posted "as is," and do not reflect AAPG editorial changes. Once the accepted manuscript appears in the Ahead of Print area, it will be prepared for print and online publication, which includes copyediting, typesetting, proofreading, and author review. This process will likely lead to differences between the accepted manuscript and the final, printed version. Manuscripts will remain in the Ahead of Print area until the final, typeset articles are printed. Supplemental material intended, and accepted, for publication is not posted until publication of the final, typeset article.

Cite as: Gervais, V., M. Ducros, and D. Granjeon, Probability maps of reservoir presence and sensitivity analysis in stratigraphic forward modeling, (in press; preliminary version published online Ahead of Print 08 November 2017): AAPG Bulletin, doi: 10.1306/0913171611517242.

Copyright (C) Preliminary Ahead of Print version 2017 by The American Association of Petroleum Geologists 


\section{Probability maps of reservoir presence and sensitivity analysis in}

\section{2 stratigraphic forward modeling}

3

7 France.

8

France.

Véronique Gervais*, Mathieu Ducros and Didier Granjeon

IFP Énergies nouvelles, 1 et 4 avenue de Bois-Préau, 92852 Rueil-Malmaison Cedex

* Corresponding author.

E-mail address: veronique.gervais@ifpen.fr (V. Gervais)

\section{Acknowledgments}

The authors would like to thank Colin North, Allegra Hosford Scheirer and an anonymous reviewer for their suggestions to improve this manuscript. Part of this work was performed using the CougarOpt prototype software developed within the framework of IFPEn's joint industry project Cougar. The authors thank the participating companies for their support: BHP Billiton, ConocoPhillips, Engie, Petrobras, Repsol and Saudi Aramco.

\section{Abstract}

One of the main objectives of petroleum exploration consists of predicting reservoir location.

Data collected in the basin are used to better understand the sedimentary architecture, but are usually insufficient to accurately characterize this architecture. Three-dimensional stratigraphic forward modeling has brought new insights in the understanding of sediment distribution. It gives the opportunity to investigate several geological models and to tackle reservoir presence probability. However, simulation time is a strong limitation to properly taking the uncertainties into account during operational studies. Here, we propose a methodology based on metamodels (or surrogate models) to perform sensitivity and risk analyses. The objective is to reduce the simulation time necessary to quantify the regional 
impact of the input parameters and to estimate probability maps of reservoir presence. The approach consists of building functions that approximate the spatial outputs of the simulator (such as sediment thickness or net-to-gross distributions in the basin) and that are fast to evaluate. These functions are then called instead of the stratigraphic forward simulator for uncertainty quantification. The proposed methodology is applied to a three-dimensional synthetic case study, considering uncertainty on input parameters related to sediment transport, accommodation space and sediment supply. The sensitivity analysis quantifies in each location the influence of the parameters on the sediment distribution, which can help to better understand the role of each uncertain process on the basin architecture. In addition, probability maps of reservoir presence are estimated. The proposed approach is a promising trade-off between simulation time and information that can be inferred.

Keywords: process-based stratigraphic simulation, uncertainty, basin modeling, basin analysis, surrogate models, metamodeling, risk analysis, potential reservoir location.

\section{Introduction}

Predicting as accurately as possible the sediment and facies distributions in a basin is critical in petroleum exploration to get robust estimations of potential reservoir location. This process is driven by the data collected in the basin. However, they are usually insufficient to accurately characterize the sediment architecture; different geological scenarios can be consistent with a single dataset. For a couple of decades, numerical stratigraphic forward models have brought a new insight on sedimentology as they make it possible to simulate physical processes related to sediment transport and deposition (e.g. Lawrence et al., 1990; Flemings and Grotzinger, 1996; Bowman and Vail, 1999; Granjeon and Joseph, 1999). They can help to better understand the effect of each process alone, or their interactions with one 
another. Parameters affecting the resultant sedimentary rock record include eustasy, grain size distribution, fluvial discharge, wave effect or sediment supply (e.g. Bonham-Carter and Sutherland, 1968; Cross, 1989; Tetzlaff and Harbaugh, 1989; Harbaugh et al., 1999; Paola; 2000; Csato et al., 2014; Granjeon, 2014). More detailed studies of the uncertainty related to the parameters describing physical processes can also be performed. Sensitivity studies make it possible to identify how these input parameters influence the simulator outputs (e.g. Bagirov and Lerche, 1999; Burgess et al., 2006; Csato et al., 2013). Calibration processes can also be considered, using either trial and error or inversion algorithms (e.g. Cross and Lessenger, 1999; Charvin et al., 2009; Falivene et al., 2014). Many stratigraphic forward simulations are usually needed to properly take uncertainty into account. For instance, the use of Monte Carlo methods to estimate the distribution of a given output property due to the uncertainty on the input parameters requires a large number of calls to the simulator. However, the number of stratigraphic models that can be investigated during a study is usually limited by the simulation time. As a result, some authors study the uncertainty related to a limited number of input parameters only, or consider a reduced sample of the parameter space, even if it narrows the information that can be retained.

In this paper, we propose an alternative approach to derive robust interpretations for petroleum exploration within a limited simulation time. We focus here on quantitative sensitivity analysis and probability of reservoir presence in each location of the basin. Our objective is to define a workflow that can be run in practice during an operational study and provide information related to uncertainty in an exploration context. To that purpose, we propose to use a methodology already applied for reservoir simulations, called metamodeling (e.g. Feraille and Marrel, 2012). We assume that the geologist has identified a set of parameters given as input to the simulator and whose values are uncertain. They will be 
referred to as "input parameters" in what follows. The proposed approach then consists in building functions computationally fast to evaluate that approximate the relationship between the input parameters and the simulator output properties. If these metamodels, also called surrogate models, predict accurately the outputs for any possible value of the input parameters, they can be used instead of the simulator for uncertainty quantification. In the context of stratigraphic forward modeling, the simulated properties can vary with the spatial location (distribution of sediment thickness or net-to-gross in the basin for instance). An extension of the metamodeling approach based on a reduced basis decomposition is then applied (Marrel and Perrot, 2012; Douarche et al., 2014; Marrel et al., 2015).

Metamodels are built from a set of simulated values, and a sufficient number of simulations is required to get accurate predictions. However, once an accurate surrogate model is obtained, different applications can be envisioned without any additional simulation. In particular, the influence of the input parameters on the output properties can be estimated at each location of the basin through a quantitative sensitivity study. Risk analysis can also be considered to estimate potential sweet spot locations for instance. In this paper, we propose to show the benefits of the approach in terms of simulation time and information inferred on the basin for exploration.

The paper outline is as follows. First, we briefly describe the stratigraphic forward model used for the simulations. Then, the metamodeling approach is presented, along with the tools used to assess the quality of the surrogate models. Finally, the potential of the proposed methodology is demonstrated for sensitivity and risk analyses on a 3D synthetic case study representative of a passive margin, based on data from the Gulf of Mexico. More precisely, the distribution of the parameter influence in the basin is obtained for accumulated sediment thickness and sand proportion. A risk analysis is also conducted following the work of 
Burgess et al. (2006), in which the presence of a reservoir is characterized by sufficiently large sediment thickness and sand proportion. The metamodeling approach makes it possible to estimate probability maps of reservoir presence.

\section{Stratigraphic forward simulation}

Stratigraphic forward simulators are increasingly used in exploration and production companies to improve predictions of reservoir and facies distributions. Several numerical models are now available, such as Delft3D (Hoogendoorn et al., 2008), Sedsim (Tetzlaff and Harbaugh, 1989) and Dionisos (Granjeon and Joseph, 1999; Granjeon, 2014). They differ in their assumptions, objectives and scales of applications. In this study, we use the Dionisos software, available as a research and commercial product (DionisosFlow ${ }^{\mathrm{TM}}$ ). However, the workflow could be applied with any other stratigraphic forward simulator.

The objective of Dionisos is to simulate transport, deposition and erosion of sediments in a wide range of depositional environments at the basin scale (10's $\mathrm{km} \times 10$ 's $\mathrm{km}$ during 10 's k.y.). The underlying forward model is based on multi grain size diffusional transport laws with gravity and water driven contributions. Erosion and deposition are controlled by sediment mass conservation and sediment transport processes. Accommodation is accounted for through subsidence and eustatic variations. Dionisos is also able to simulate carbonate deposition using environmental laws of production such as wave effects or bathymetry (Seard et al., 2013).

\section{Methodology for uncertainty quantification}

In what follows, we consider that input parameters are modeled as independent random variables with given probability distributions. These distributions can be uniform or normal for instance, and are defined according to the knowledge of the geologist. The objective of the 
proposed workflow is to study the impact of this uncertainty on the sedimentary architecture of the basin. In this paper, we focus on spatial output properties such as the sediment distribution in the basin. However, other outputs such as properties along wells could also be considered. Many forward simulations are usually required to properly take uncertainty into account. A way to limit their number consists in building functions that approximate the relationship between the input parameters and the simulator outputs. If these functions provide accurate predictions for any values of the parameters within their uncertainty range, they can be used instead of the simulator for sensitivity and risk analysis for instance. The proposed workflow is summarized in Figure 1. The main steps are available in the CougarOpt research software, dedicated to uncertainty management and developed within the framework of joint industry projects (see e.g. Feraille and Marrel (2012) for more details).

\section{Metamodeling approach}

Metamodels, also referred to as surrogate models or response surfaces, can be used to approximate scalar outputs of a simulator. They are built from a set of values of the output the training set - simulated for a sample of the input parameter space, called design of experiments. The metamodels then only require a small computation time to provide an estimation of the output for any other parameter value. Several methods can be considered to build metamodels: polynomial regression, regression splines, neural network or Gaussian processes for example. Here, we refer to the last approach: estimations are obtained by kriging interpolation of the simulated values. More details can be found in Sacks et al. (1989) or Forrester and Keane (2009), for example.

In practice, the choice of the design of experiments is a key issue to optimize the simulation time necessary to build accurate metamodels. The number of simulations needed to get predictive estimations is unknown a priori. It depends on the number of parameters, the complexity of the relationship between these parameters and the output. If selecting a small 
design, the metamodel may lack accuracy in some parts of the parameter space. Considering larger designs should improve the predictivity of the metamodel, but at the cost of longer simulation times. Designs of experiments are generated here following the Latin hypercube sampling (LHS) method (McKay et al., 1979). This approach takes the input parameter distribution into account and provides space-filling designs. In addition, all the parameters vary simultaneously and the size of the sample is chosen by the user.

Many outputs of stratigraphic forward models vary with location in the basin (e.g. the distribution of the sediment thickness). These spatial properties can be decomposed as a set of scalar outputs in each grid block. As a result, they can be approximated by a set of metamodels, one per scalar output. However, the induced computation time can be significant for a large number of grid blocks. The methodology described in Marrel et al. (2015) and Douarche et al. (2014) can be considered to overcome this limitation. It extends the kriging approach to functional outputs and encompasses the following steps:

1. Principal component analysis decomposition

First, we refer to the Karhunen-Loève decomposition (Loève, 1978). The functional output $y(x, \theta)$ can be viewed as an infinite linear combination of orthonormal basis functions $\phi_{k}$ :

$$
y(x, \theta)=m(x)+\sum_{k=1}^{\infty} \alpha_{k}(\theta) \phi_{k}(x)
$$

In this decomposition, $x$ represents the spatial location, $\theta$ the input parameters, $m$ the mean and $\alpha_{k}$ the projection coefficient on the basis function $\phi_{k}$. The parameters only influence the projection coefficients $\alpha$. With this formulation, the dependences on the input parameters and spatial location are thus decoupled. 
In practice, estimating such decomposition boils down to perform a principal component analysis on the training set $y\left(x, \theta_{i}\right)_{i=1 . . n}$ :

$$
y\left(x, \theta_{i}\right)=\widehat{m}(x)+\sum_{k=1}^{M} \hat{\alpha}_{k}\left(\theta_{i}\right) \hat{\phi}_{k}(x) \text { for } i=1 \ldots n
$$

$$
y^{*}(x, \theta)=\widehat{m}(x)+\sum_{k=1}^{L} \hat{\alpha}_{k}^{*}(\theta) \hat{\phi}_{k}(x)
$$

186 We refer to this approach in what follows. 


\section{Quality assessment}

To assess the quality of the predictor $y^{*}(x, \theta)$, we introduce an additional sample of the input parameter space - the test sample. The values simulated for the corresponding stratigraphic forward models are compared to the ones given by the predictor. This provides a quantitative estimation of the predictor quality, the so-called Q2 coefficient. It is defined at each location $x$ by:

$$
Q 2(x)=1-\frac{\sum_{j=1}^{n t}\left(y\left(x, \theta_{j}\right)-y^{*}\left(x, \theta_{j}\right)\right)^{2}}{\sum_{j=1}^{n t}\left(y\left(x, \theta_{j}\right)-\bar{y}(x)\right)^{2}}
$$

$\left(\theta_{j}\right)_{j=1 . . n t}$ represents the test sample and $\bar{y}(x)$ the mean of the corresponding simulated values $y\left(x, \theta_{j}\right)_{j=1 . . n t}$ at location $x$. The numerator is the sum of the least-square errors between the predicted and simulated output values for the test sample. The denominator introduces a normalization by the output variance. The Q2 coefficient is less than 1 and decreases when the error increases. In the case of the reduced basis decomposition considered here (equation 3), the Q2 coefficient reflects both the truncation and metamodeling errors.

\section{Uncertainty quantification}

Once an accurate predictor is obtained for the output property of interest, it can replace the simulator to perform sensitivity analysis and uncertainty propagation. No additional simulation is required.

The sensitivity analysis consists of estimating the influence of the input parameters on the output property of interest. It can help to better understand the processes at work in the different parts of the basin, or to discard the less influential parameters in a calibration process. Here, we propose to perform a quantitative sensitivity analysis based on Sobol' indices (Sobol', 1990). These indices measure the part of the output variance due to the 
parameters or their interactions. The first order index, or primary effect, quantifies the part of the output variance explained by a parameter alone. Higher order indices are related to parameter interaction effects that are not included in first order indices. The Sobol' indices vary between 0 and 1 . They get closer to one when the part of the output variance explained by the parameters increases. The sum of all the Sobol' indices involving a given parameter is called the total effect (Homma and Saltelli, 1996). It estimates the global sensitivity of the output to the parameter.

Sobol' indices are associated with a given scalar output. For spatial properties, these indices can be estimated in each grid block, which then provides the distribution of the parameter influence in the basin.

Finally, the uncertainty on the input parameters can be propagated to the output property of interest. To that purpose, the parameters are sampled according to their distributions (MonteCarlo method for instance), and the corresponding values of the output are estimated from the surrogate models. To analyze the resulting output sample, percentiles can be computed in each grid block. Probabilities to meet some criteria, defining for instance a potential reservoir, can also be estimated at each location.

\section{Application to a geological case study}

\section{Case study}

The potential of the proposed workflow is illustrated on a 3D synthetic case study based on data from the Gulf of Mexico (Burgess et al., 2006). The model represents a clastic passive margin of $1000 \mathrm{~km} \times 1000 \mathrm{~km}(621 \mathrm{mi} \times 621 \mathrm{mi})$ which consists of a continental shelf, margin slopes, a basin floor with some relief and a submarine canyon. The initial bathymetry is given in Figure 2. 
The basin is discretized into $50 \times 50$ grid blocks with a resolution of $20 \mathrm{~km}(12.4 \mathrm{mi})$. This resolution is larger than the one are generally considered (1 to $10 \mathrm{~km}(0.6$ to $6.2 \mathrm{mi})$ for clastic environments for instance). However, our objective was to illustrate the potential of the proposed approach, which applies in the same way whatever the size of the grid blocks. The basin infill is simulated with Dionisos during a period of 3 m.y. with time steps of 0.2 m.y.. A sediment source of 3 cells wide is assumed on the western margin (Figure 2). The sediment input is composed of a constant supply of mud and sand. The sediments are distributed in the basin according to gravity-driven and water-driven diffusional processes. Eustatic oscillations are represented by a sinusoid. Basin deformation is related to subsidence rate and flexural isostasy defined by an elastic plate thickness of $30 \mathrm{~km}(18.6 \mathrm{mi})$. Finally, mechanical compaction applies to the deposited sediments with respect to the sand/mud ratio.

The uncertainty considered in this study is related to the three major processes that affect the sedimentary architecture of the basin: accommodation, sediment and water supplies, and sediment transport. Uncertainty on accommodation is accounted for through a uniform subsidence rate and the amplitude and period of eustatic variations. Uncertainty on supplies is characterized by the variations in total sediment volume inflow, sand/mud proportion and water discharge. Last, a reference transport coefficient is introduced to take the uncertainty on the diffusional processes and water discharge into account. This reference coefficient characterizes the water-driven diffusion of sand in the marine environment and drives the perturbation of all other water-driven transport coefficients together with two additional parameters: the ratio between the mud and sand diffusion coefficients, and the ratio between the continental and marine diffusion coefficients. This parameterization reduces the number of unknowns and prevents the simulation of inconsistent scenarios (e.g. better transport of 
sand than mud). Also, the parameters are related to a physical process, so that the results are more easily related to the physics of the problem.

Input parameters are assigned uniform distributions and the ranges of variation given in Table

1. These intervals were deduced from the values considered in Burgess et al. (2006). The gravity diffusion coefficients are held constant at $0.01 \mathrm{~km}^{2} / \mathrm{k} . \mathrm{y} .\left(0.0038 \mathrm{mi}^{2} / \mathrm{k} . \mathrm{y}.\right)$. The uncertainty on compaction is not considered here as it was expected to have a much lower impact on accommodation compared to eustastic variations.

\section{Metamodeling}

A set of simulations is required to build metamodels. In this study, four training sets of size 30, 60, 90 and 120 are generated following the Latin hypercube sampling (LHS) method. An additional LHS of 50 simulations - the test sample - is also generated to assess the quality of the metamodels.

Two output properties are considered: a map of sediment thickness defined as the accumulated thickness of deposited sediments in each column of the grid, and a map of sand proportion defined as the total proportion of sand in each column of the grid. These property maps are used to characterize potential reservoirs in the basin. Their mean and standard deviation in the test sample after a simulation period of 0.4 and 3 m.y. are given in Figure 3. For this figure and the following ones, the values are mapped on the average topography computed on the test sample after 0.4 and 3 m.y., respectively. In addition, unfilled grid blocks indicate areas with no deposition. At the beginning of the simulation period (0.4 m.y.), sediments are mainly deposited in the delta near the input source (indicated by the white arrow), the submarine canyon and the western margin toe-of-slope (Figure 3A). These regions also correspond to the highest sand proportion (Figure 3E). At this time, no deposition has 
occurred on the relief of the basin floor (Figure 3A). After 3 m.y., the submarine canyon has generally been filled and the topography of the western margin is globally symmetrical with respect to the input source (Figure 3C). The sediment deposition has spread around the entry point, and the basin relief is covered with sediments for some simulations. Sand is still mainly located near the source and on the western margin (Figure 3G).

To approximate the sediment thickness and sand proportion, a principal component analysis is performed on each training set (equation 2). Only the components necessary to explain $98 \%$ of the output variance are retained. Then, kriging-based surrogate models are computed for the projection coefficients associated to the reduced bases (equation 4). The metamodeling approach is applied to the values simulated after 0.4 and 3 m.y.. The quality of the resulting predictors for the sediment thickness and sand proportion is estimated from the 50 simulations of the test sample. The resulting values of the Q2 coefficients (equation 5) are given in Figure 4. The Q2 coefficient cannot be computed in the grid blocks where deposition never occurs in the test sample, so that no values are displayed (unfilled grid blocks).

Globally, the two properties are better predicted when the size of the training set increases (larger values of the Q2 coefficient). The regions with less accuracy are located on the boundary of the deposition area and in distal parts of the basin, where sediments are deposited in a few simulations only. The predictions are globally more accurate for sediment thickness than for sand proportion, with larger values of the Q2 coefficient. With the proposed approach, sand proportion thus appears more difficult to estimate than sediment thickness for the same LHS. However, the predictions obtained with the largest training set are globally accurate in the regions with a significant deposition of sand (Figures 3B, 3D, 3F, 3G and 4D, 4H, 4L, 4P). 
307 The quality of the metamodels is also illustrated in Figure 5, which shows the distribution of the true and predicted values of sand proportion after 0.4 and 3 m.y. for two models of the test sample. The general trends are captured with only 30 models. However, considering a larger training set makes it possible to predict more accurately the distribution.

\section{Sensitivity analysis}

A variance-based sensitivity study was performed on the spatial distribution of sediment thickness and sand proportion, using the training set of 120 models. Figure 6 shows the total effect on these properties for the most influential parameters.

The sediment supply, water discharge and reference diffusion coefficient have a significant influence on both the sediment thickness and sand proportion distribution (large total effect, see Figures $6 \mathrm{~A}$ to $6 \mathrm{~L}$ ). The sediment supply is globally the most influential parameter for the sediment thickness, with a dominant impact on the outer part of the delta (at 0.4 m.y.) and the western margin (Figures $6 \mathrm{~A}$ and $6 \mathrm{~B}$ ). The sand proportion deposited in the delta and the western margin is mainly influenced by the sand proportion in the input source (Figures $6 \mathrm{O}$ and $6 \mathrm{P}$ ), whereas the values in the more distal part of the basin appear driven by the mud/sand diffusion coefficient ratio (Figures 6S and 6T). The water discharge and reference diffusion

326 coefficient have an equivalent impact, which is spatially distributed where the three above 327 parameters have a lower influence (Figures 6E to 6L). Finally, the eustasy amplitude has an 328 impact on the sediment thickness around the sediment entry point at the beginning of the simulation period (Figure 6M), but this effect disappears after some time (Figure $6 \mathrm{~N}$ ). On the 
contrary, the subsidence rate becomes more influential through time in this area (Figures 6Q and 6R).

The information provided by sensitivity analyses can help to better choose the parameters to be tuned in the calibration step. For instance, if well data are available, these parameters may be different depending on the location of the well.

\section{Risk analysis}

The predictors for sediment thickness and sand proportion can also be used to perform risk analysis, for instance to study the location of potential reservoirs. Indeed, the probability distribution of these outputs due to the uncertainty on the input parameters can be estimated by sampling the distribution assigned to each input parameter and computing the corresponding values predicted by the surrogate models.

We consider here a Monte Carlo sample of the parameter space. The metamodels built with the training set of size 120 are used to estimate the corresponding sample of the sediment thickness and sand proportion distributions in the basin. Various analyses can then be performed on this sample.

First, percentiles can be estimated in each grid block. For instance, the maps of P5 and P95 percentiles for the sediment thickness at 3 m.y. are given in Figure 7. As evidenced in Figure 7B, at least $300 \mathrm{~m}(984 \mathrm{ft})$ of sediments are deposited in the delta and the submarine canyon for $95 \%$ of the sample. In addition, the probability to reach a sediment thickness of at least $1000 \mathrm{~m}(3281 \mathrm{ft})$ on the western margin is about 5\% (Figure 7D). 
The Monte Carlo sample can also be used to estimate in each grid block the probability to meet some physical criteria. Following Burgess et al. (2006), we can identify potential reservoir zones characterized by sufficiently large sediment thickness and sand proportion. We consider here the probability to obtain a sediment thickness larger than $60 \mathrm{~m}(197 \mathrm{ft})$ and a sand proportion greater than $25 \%$ after 3 m.y.. The resulting maps are given in Figures $8 \mathrm{~A}$ and $8 \mathrm{~B}$, together with the probability to meet the two criteria (Figure $8 \mathrm{C}$ ). The region with a probability larger than $50 \%$ to be a reservoir zone is displayed in black in Figure $8 \mathrm{D}$. It consists of the delta, the submarine canyon and the western margin toe-of-slope.

Finally, the parameter distribution corresponding to the sub-sample that meets the above criteria provides additional information on the dynamic system. It complements the sensitivity analysis by providing trends for parameter values that result in potential reservoir zones. For instance, we consider here three points $\mathrm{A}, \mathrm{B}$ and $\mathrm{C}$ located in the delta, the submarine canyon and the western margin toe-of-slope, respectively (Figure $8 \mathrm{C}$ ). The values of the input parameters for which the sediment thickness exceeds $60 \mathrm{~m}$ and the sand proportion exceeds $25 \%$ at these locations are given in Figure 9 to Figure 11 . The potential reservoirs in grid block A correspond to sufficiently large values for the source sand proportion, and more often to a large sediment supply. The reservoirs in grid block B (submarine canyon) are mainly characterized by a sufficiently large sand proportion in the input source. Finally, the reservoirs in grid block $\mathrm{C}$, located on the western margin toe-of-slope, correspond to sufficiently large values for the source sand proportion, and more often to large values of the sediment supply, water discharge and reference diffusion coefficient. The results obtained here are consistent with the quantitative sensitivity analysis (Figure 6). Indeed, the subsample of the parameters that were not identified as influential at locations $\mathrm{A}, \mathrm{B}$ and $\mathrm{C}$ remain close to uniform. On the contrary, the distributions of the most influential parameters are completely different from the 
initial ones. The analysis presented here also provides information that could help for the calibration process. For instance, if data were available at location A stating the presence of a reservoir (as defined with the above criteria), the uncertainty range of the sand proportion could be reduced for calibration.

\section{Conclusions and perspectives}

In this work, we propose an approach to take into account the uncertainty on the stratigraphic model input parameters from a limited number of stratigraphic forward simulations. It consists in building metamodels that approximate the relationship between the input parameters and the outputs of the simulator. These metamodels are built by kriging interpolation of the output values simulated for a sample of the input parameter space. They provide estimations of the output for all other values of the parameters. If these estimations are close to the true (simulated) values, they can be used for uncertainty quantification. In particular, they make it possible to apply quantitative sensitivity analysis algorithms and Monte Carlo methods without additional simulation.

The method is illustrated on a $3 \mathrm{D}$ synthetic case representative of a passive margin. It provides globally accurate predictions of the accumulated sediment thickness and sand proportion deposited in the basin from a limited simulation time. Using these metamodels, we estimate the influence of the input parameters at all locations. This information can help to discriminate among the various geological processes occurring in the formation of the sedimentary architecture. It also paves the way for new interpretations related to basin physiography and geological processes that provide guidelines for the model calibration. Finally, the metamodels are used to estimate probability maps of reservoir presence. In practice, the proposed workflow can be run automatically except for the size of the 
experimental design. In the future, it would be interesting to introduce an automatic definition of this design, using for instance sequential approaches. They consist in complementing iteratively an initial sample with new simulations judiciously chosen.

Interpretations of the results should be related to the assumptions and formulations of the stratigraphic forward model and to the choice of the uncertainty (parameters and range of variation). In the test case considered here, the choice of the input parameters was driven by a previous study. In practice, many parameters are potentially unknown. In that case, it is recommended to discard first the non-influential ones before running the proposed workflow. This can be achieved from a limited number of simulations using for instance screening methods.

The results of our approach can be easily integrated in a study and should be seen as complementary to other kinds of studies (seismic interpretations, well correlation, sequencestratigraphy). They can help petroleum geologists to prospect their basin and determine the most probable locations of adequate reservoir rock in the context of relatively unknown basin architectures. In particular, the proposed approach can help to identify a few geological scenarios representing the model uncertainty. These scenarios can then be used to initialize basin models with sedimentary facies maps, obtained from a classification of the stratigraphic model continuous outputs (sand proportion, bathymetry for instance) into basin model lithologies. 


\section{References}

427 Bagirov, E., and I. Lerche, 1999, Probability and sensitivity analysis of two-dimensional basin modeling results, in J. W. Harbaugh, W. L. Watney, E. C. Rankey, R. Slingerland and R. H. Goldstein, eds., Numerical experiments in stratigraphy: Recent advances in stratigraphic and sedimentologic computer simulations: SEPM Special Publication 62, p. $35-68$.

Bonham-Carter, G., and A. J. Sutherland, 1968, Mathematical model and FORTRAN IV program for computer simulation of deltaic sedimentation: Computer Contribution, 24, Kansas Geological Survey, Lawrence, Kansas, 56 p.

Bowman, S. A., and P. R. Vail, 1999, Interpreting the stratigraphy of the Baltimore canyon Section, offshore New Jersey with PHIL, a stratigraphic simulator, in J. W. Harbaugh, W. L. Watney, E. C. Rankey, R. Slingerland and R. H. Goldstein, eds., Numerical Experiments in Stratigraphy: recent advances in stratigraphic and sedimentologic computer simulations, SEPM Special Publication 62, p. 117-138.

Burgess, P. M., H. Lammers, C. van Oosterhout, and D. Granjeon, 2006, Multivariate sequence stratigraphy: Tackling complexity and uncertainty with stratigraphic forward modeling, multiple scenarios and conditional frequency map: AAPG Bulletin, v. 90, no. 12, p. 1883-1901.

Charvin, K., G. J. Hampson, K. Gallagher, and R. Labourdette, 2009, A Bayesian approach to inverse modeling of stratigraphy, part 1: method: Basin Research, v. 21, p. 5-25.

Cross, T. A., 1989, Quantitative Dynamic Stratigraphy, Englewoods Cliff, NJ, Prentice Hall, $624 \mathrm{p}$.

Cross, T. A. and M. Lessenger, 1999, Construction and application of stratigraphic inverse model. In: Numerical Experiments in Stratigraphy: Recent Advances in Stratigraphic and Sedimentologic Computer Simulations, in J. W. Harbaugh, W. L. Watney, E. C. 
Rankey, R. Slingerland, and R. H. Goldstein, eds, Numerical Experiments in Stratigraphy: recent advances in stratigraphic and sedimentologic computer simulations, SEPM Special Publication 62, p. 69-83.

Csato, I., D. Granjeon, O. Catuneanu, and G. R. Baum, 2013, A three-dimensional stratigraphic model for the Messinian crisis in the Pannonian Basin, eastern Hungary': Basin Research, v. 25, no. 2, p. 121-148.

Csato, I., O. Catuneanu, and D. Granjeon, 2014, Millennial-scale sequence stratigraphy: numerical simulation with Dionisos: Journal of Sedimentary Research, v. 84, no. 5, p. $394-406$.

Douarche, F., S. Da Veiga, M. Feraille, G. Enchéry, S. Touzani, and R. Barsalou, 2014, Sensitivity Analysis and Optimization of Surfactant-Polymer Flooding under Uncertainties: Oil \& Gas Science and Technology - Rev. IFP Energies nouvelles, v. 69, no. 4 , p. 603-617.

Falivene, O., A. Frascati, S. Gesbert, J. Pickens, Y. Hsu, and A. Rovira, 2014, Automatic calibration of stratigraphic forward models for predicting reservoir presence in exploration: AAPG Bulletin, v. 98, no. 9, p. 1811-1835.

Feraille, M., and A. Marrel, 2012, Prediction under Uncertainty on a Mature Field: Oil \& Gas Science and Technology - Revue d'IFP Energies Nouvelles, v. 67, no. 12, p. 193-206.

Flemings, P. B., and J. P. Grotzinger, 1996, STRATA: Freeware for analyzing classic stratigraphy problems: GSA Today, v. 6, no. 12, p. 1-7.

Forrester, A. I. J., and A. J. Keane, 2009, Recent advances in surrogate-based optimization: Progress in Aerospace Sciences, vol. 45, no. 1-3, p. 50-79.

Granjeon, D. and P. Joseph, 1999, Concepts and applications of a 3-D multiple lithology, diffusive model in stratigraphic modeling, in J. W. Harbaugh, W. L. Watney, E. C. Rankey, R. Slingerland, and R. H. Goldstein, eds, Numerical Experiments in 
Stratigraphy: recent advances in stratigraphic and sedimentologic computer simulations, SEPM Special Publication 62, p. 197-210.

Granjeon, D., 2014, 3D forward modelling of the impact of sediment transport and base level cycles on continental margins and incised valleys, in A.W. Martinius, R. Ravnas, J.A. Howell, R.J. Steel and J.P. Wonham, eds, From Depositional Systems to Sedimentary Successions on the Norwegian Continental Margin, International Association of Sedimentologists, Spec. Publ., v. 46, p. 453-472.

Harbaugh, J. W., L. W. Whatney, E. Rankay, R. Slingerland, R. Goldstein, and E. Franseen, 1999, Numerical experiments in stratigraphy: recent advances in stratigraphic and computer simulations. SEPM special publication, v. 62, 362 p.

Homma T., and A. Saltelli, 1996, Importance measures in global sensitivity analysis of model output: Reliability Engineering and System Safety, v. 52, no. 1, p. 1-17.

Hoogendoorn, R. M., I. Overeem, and J. E. A. Storms, 2008, Process-response modelling of fluvio-deltaic stratigraphy: Computers \& Geosciences, vol. 34, no. 10, p. 1394-1416.

Lawrence, D. T., M. Doyle, and T. Aigner, 1990, Stratigraphic simulation of sedimentary basins: concepts and calibration: AAPG Bulletin, v. 74, no. 3, p. 273-295.

Loève, M., 1978, Probability Theory, vols. I-II.: New York, Springer, 416 p.

Marrel, A. and N. Perot, 2012, Development of a surrogate model and sensitivity analysis for an atmospheric dispersion computer code: Proceedings of PSAM 11 \& ESREL 2012 Conference, Helsinki, Finland, June 2012.

Marrel, A., N. Perot, and C. Mottet, 2015, Development of a surrogate model and sensitivity analysis for spatio-temporal numerical simulators: Stochastic Environment Research and Risk Assessment, vol. 29, no. 3, p. 959-974. 
McKay, M. D., R. J. Beckman, and W. J. Conover, 1979, Comparison of Three Methods for Selecting Values of Input Variables in the Analysis of Output from a Computer Code: Technometrics, vol. 21, no. 2, p. 239-245.

Morris, M. D., 1991, Factorial sampling plans for preliminary computational experiments: Technometrics, vol. 33, no. 2, p. 161-174.Paola, C., 2000, Quantitative models of sedimentary basin filling: Sedimentology, v. 47, Issue s1, p. 121- 178.

Paola, C., 2000, Quantitative models of sedimentary basin filling: Sedimentology, v. 47, Issue s1, p. $121-178$.

Sacks, J., W. J. Welch, T. J. Mitchell, and H. P. Wynn, 1989, Design and Analysis of Computer Experiments: Statistical Science, vol. 4, no. 4, p. 409-423.

Seard, C., J. Borgomano, D. Granjeon, and G. Camoin, 2013, Impact of environmental parameters on coral reef development and drowning: Forward modelling of the last deglacial reefs from Tahiti (French Polynesia; IODP Expedition \#310): Sedimentology, vol. 60 , no. 6 , p. $1357-1388$.

Sobol', I. M., 1990, On sensitivity estimation for nonlinear mathematical models: Mathematical Modeling \& Computational Experiment, vol. 1, no. 4, p. 407-414.

Tetzlaff, D. M. and J. W. Harbaugh, 1989, Simulating clastic sedimentation: New York, Springer US, $202 \mathrm{p}$.

\section{Authors}

Véronique Gervais joined the Geosciences division of IFP Energies Nouvelles in 2005. She received her Ph.D. in applied mathematics from the University of Aix-Marseille in 2004. She is involved in projects on uncertainty quantification and assisted history-matching in Geosciences. 
Mathieu Ducros is a geologist with 10 years of experience in petroleum exploration. He obtained a M.Sc. degree from the École des Mines de Saint-Etienne in 2007. He started his career in Beicip-Franlab before joining IFPEN in 2010. Since then he works on improving basin modeling tools for better assessment of exploration risks.

Didier Granjeon joined the Sedimentology Group at IFP Energies Nouvelles in 1992. He received his Ph.D. in geology from the University of Rennes in 1996. He has been involved in basin studies from seismic and outcrop interpretation to numerical modeling. His work has been focused on the research and development of a three-dimensional stratigraphic forward model.

\section{Figure captions}

Figure 1 - Workflow for uncertainty quantification.

Figure 2 - Initial bathymetry, with a vertical exaggeration of 200. The location of the sediment input source on the western margin is indicated by the large white arrow.

Table 1 - Uncertainty range for the input parameters.

Figure 3 - Average (top) and standard deviation (bottom) computed on the test sample (50 models) for the accumulated sediment thickness (left) and sand proportion (right) deposited after 0.4 and 3 m.y.. In this figure and all subsequent ones, the results presented at 0.4 and 3 m.y. are mapped on the average topography computed on the test sample at 0.4 and 3 m.y., respectively, with a vertical exaggeration of 200. Sedimentation never occurs in the unfilled grid blocks. The white arrow indicates the sediment input source location.

Figure $4-$ Q2 coefficient computed with the training sets of size 30, 60, 90 and 120 for the accumulated sediment thickness and sand proportion deposited after 0.4 and 3 m.y.. The values are not displayed in the grid blocks where sediment deposition never occurs in the test sample (unfilled grid blocks).

Figure 5 - Sand proportion simulated (first column) and predicted for two models of the test sample after 0.4 and 3 m.y., considering metamodels built from the training sets of size 30 (second column) and 120 (third column).

Figure 6 -Total effect computed for the input parameters that have a significant influence on the accumulated sediment thickness (left) and sand proportion (right) in the basin after 0.4 and 3 m.y.. The training set of size 120 is used to predict the properties. The values are not displayed in the grid blocks where sediment deposition never occurs in the training set (unfilled grid blocks). 
Figure 7 - P5 (top) and P95 (bottom) percentiles estimated for the sediment thickness after 3 m.y.. The maximum value of the color scale is limited to $300 \mathrm{~m}$ and $1000 \mathrm{~m}$ in figures (b) and (d) for the P5 and P95 percentiles, respectively. The values are not displayed in the grid blocks where sediment deposition never occurs in the training set (unfilled grid blocks).

559 Figure 8 - Estimated probability of meeting various criteria after $3 \mathrm{~m} . \mathrm{y}$. The values are not 560 displayed in the grid blocks where sediment deposition never occurs in the training sample 561 (unfilled grid blocks).

562 Figure 9 - Parameter distribution in the set of models for which the sediment thickness is 563 larger than $60 \mathrm{~m}$ and the sand proportion greater than $25 \%$ in grid block A.

564 Figure 10 - Parameter distribution in the set of models for which the sediment thickness is 565 larger than $60 \mathrm{~m}$ and the sand proportion greater than $25 \%$ in grid block B.

566 Figure 11 - Parameter distribution in the set of models for which the sediment thickness is 567 larger than $60 \mathrm{~m}$ and the sand proportion greater than $25 \%$ in grid block $\mathrm{C}$. 
Table 1

\begin{tabular}{|c|c|c|c|}
\hline \multicolumn{2}{|r|}{ Input parameters } & Minimum value & Maximum value \\
\hline \multirow{3}{*}{ Accommodation } & Eustasy-Period (m.y.) & 0.5 & 2 \\
\hline & Eustasy-Amplitude (m) & $5(16.4 \mathrm{ft})$ & $50(164 \mathrm{ft})$ \\
\hline & Subsidence rate & 25 (82 ft/m.y.) & 75 (246 ft/m.y.) \\
\hline \multirow{3}{*}{ Sediment supply } & Source - supply $\left(\mathrm{km}^{3} / \mathrm{m} . \mathrm{y}.\right)$ & $\left.\mathrm{mi}^{3} / \mathrm{m} . \mathrm{y}.\right)$ & $\left.\mathrm{mi}^{3} / \mathrm{m} . \mathrm{y}.\right)$ \\
\hline & Source - sand proportion & 10 & 40 \\
\hline & Water discharge $(\%)$ & 50 & 200 \\
\hline \multirow{3}{*}{ Sediment transport } & $\begin{array}{l}\text { Sand marine diffusion coefficient - } \\
\text { reference coefficient }\left(\mathrm{km}^{2} / \mathrm{k} . \mathrm{v}\right)\end{array}$ & $\left.\mathrm{mi}^{2} / \mathrm{k} . \mathrm{y}.\right)$ & $2\left(0.77 \mathrm{mi}^{2} / \mathrm{k} . \mathrm{y}.\right)$ \\
\hline & $\begin{array}{c}\text { Continental/marine diffusion } \\
\text { coefficeint ration }(-)\end{array}$ & 50 & 100 \\
\hline & $\begin{array}{c}\text { Mud/sand diffusion coefficient } \\
\text { ration }(-)\end{array}$ & 1.5 & 4.5 \\
\hline
\end{tabular}


Identify model parameters with uncertain values (input parameters) and assign them a probability distribution

\section{Input probability distributions}

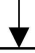

Generate a sample of the input parameter space (design of experiments)

\section{Design of experiments}

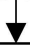

Perform stratigraphic forward simulations for the models of the design of experiments to form the training set

\section{Training set}

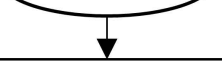

Compute metamodels approximating the outputs of interest of the simulator

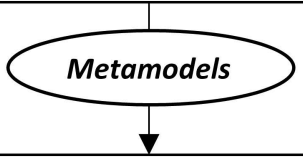

Use the predictions provided by the metamodels to perform sensitivity and risk analyses 
Sediment input source

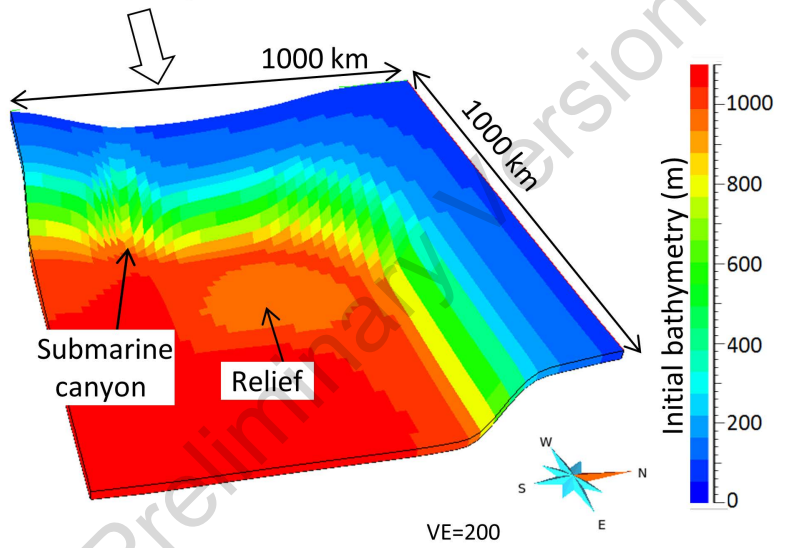




\section{Sediment thickness}

\}$^{0.4 \mathrm{~m} \cdot \mathrm{y}}$.

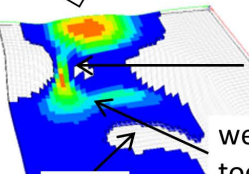

relief toe-of-slope

(A)

canyon

Average (m)
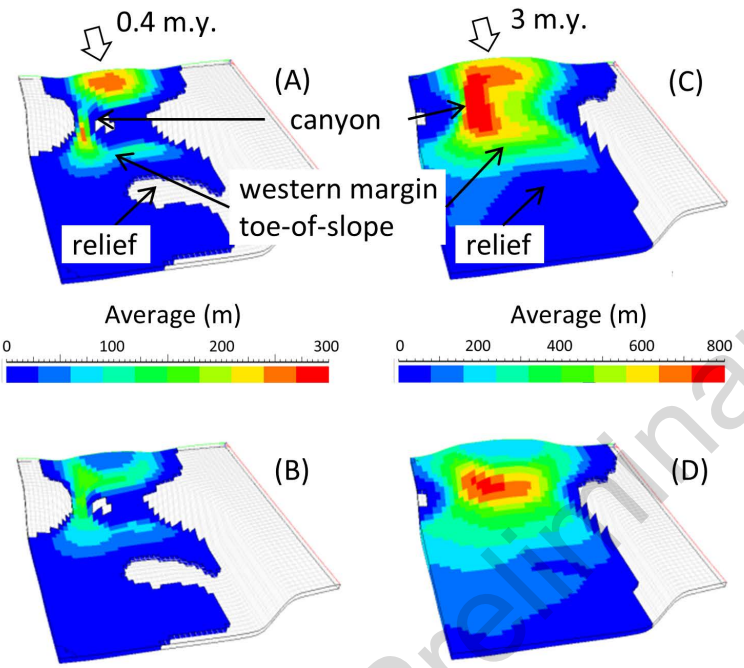

Standard deviation

0 50
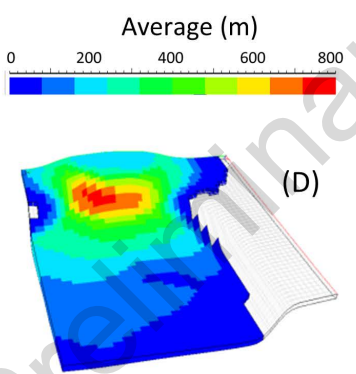

Standard deviation $\begin{array}{llll}100 & 200 & 300 & 400\end{array}$

\section{Sand proportion}
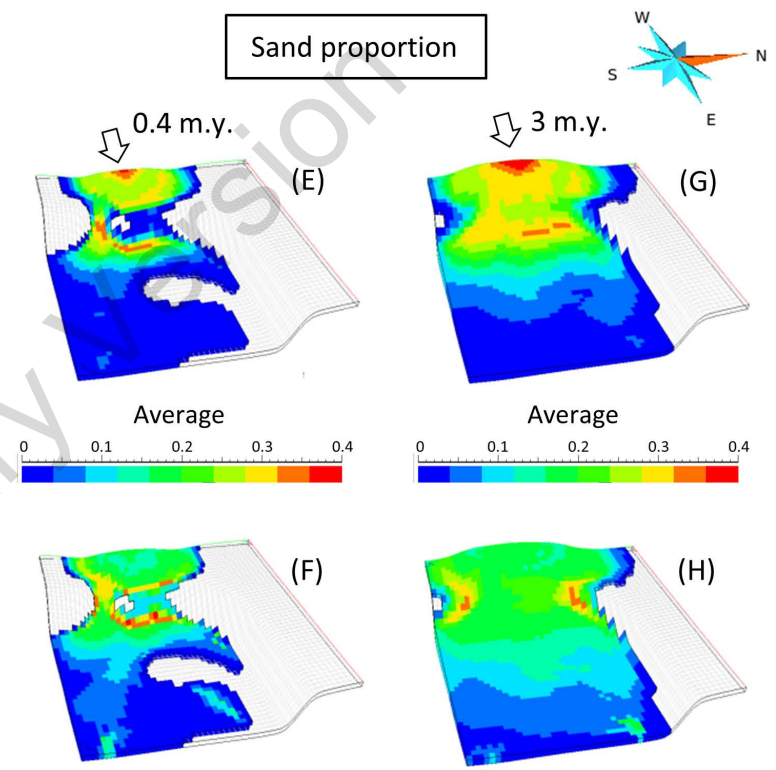

Standard deviation

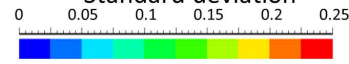

Standard deviation

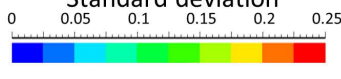


Simulations
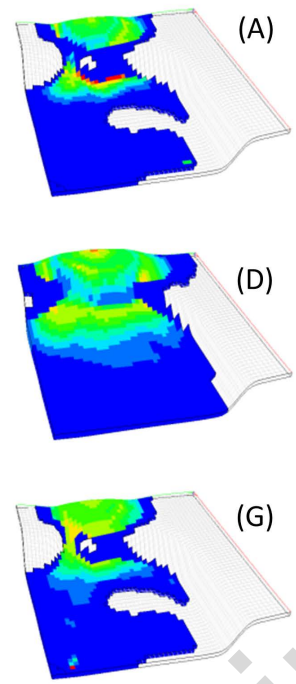

\section{Predictions from 30 models}

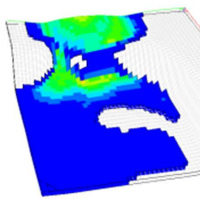

(B)
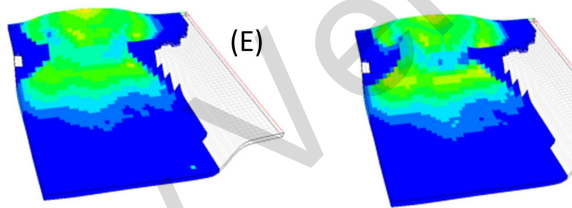

(F)

Model 1 3 m.y.

Model 2 0.4 m.y.

Model 2 3 m.y.

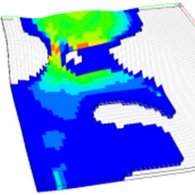

(I)

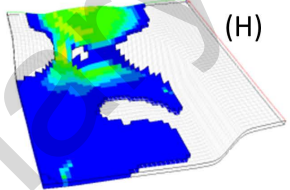

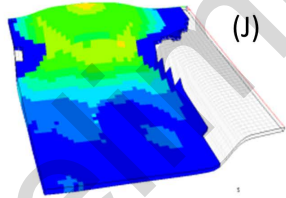
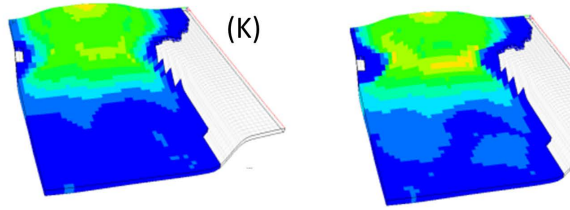

(L)
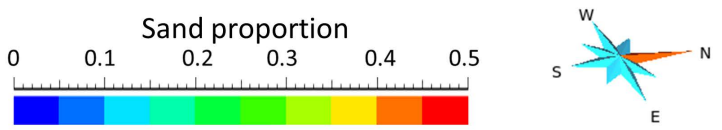
(A) Percentile P5

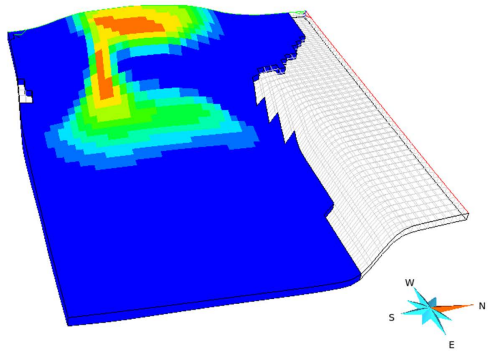

Sediment thickness $(\mathrm{m})$

200

400

600

(C) Percentile P95

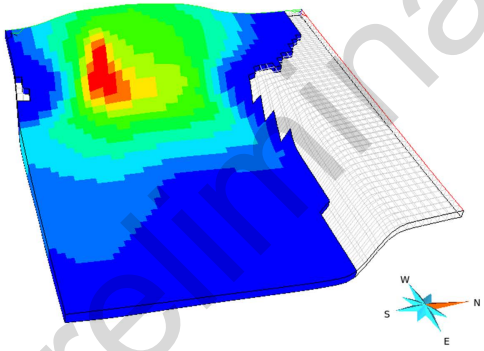

Sediment thickness ( $m$ )

0

400

800

1200
(B) Percentile P5 - truncated colorscale

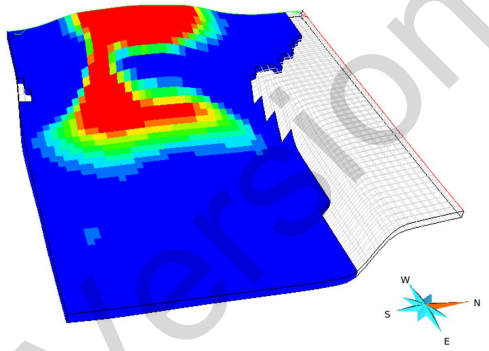

Sediment thickness $(\mathrm{m})$

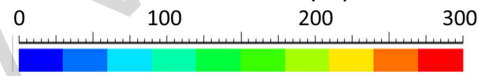

(D) Percentile P95 - truncated colorscale

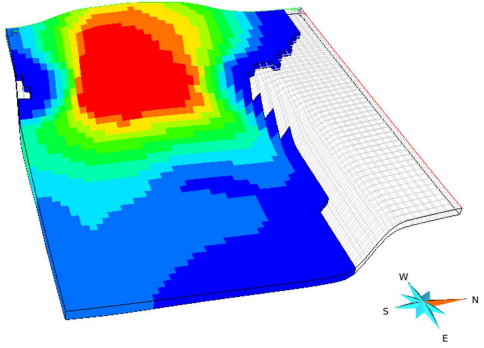

Sediment thickness (m)

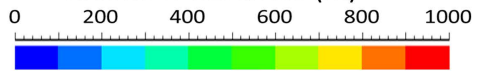


(A) Sediment thickness $>60 \mathrm{~m}$

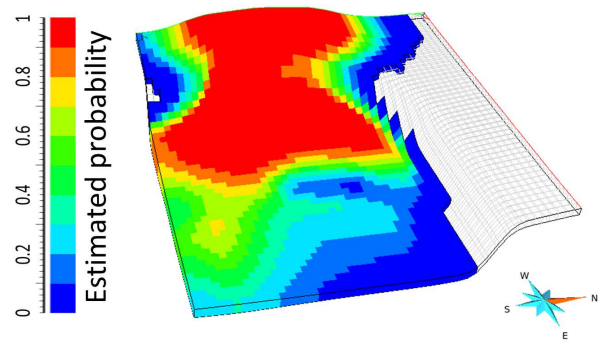

(C) Sediment thickness $>60 \mathrm{~m}$ and sand proportion $>25 \%$

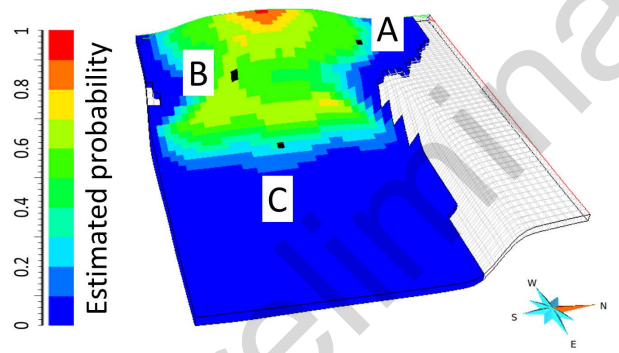

(B) Sand proportion $>25 \%$

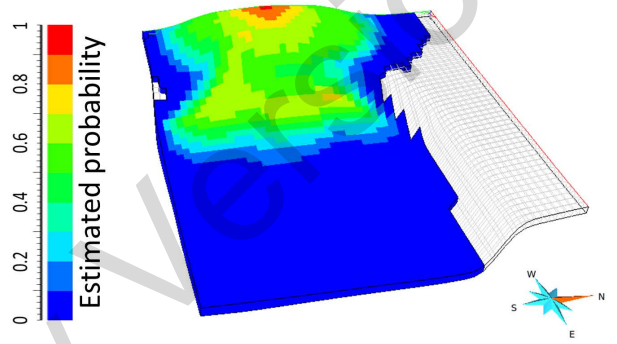

(D) Region with a probability larger than $50 \%$ to meet the two criteria

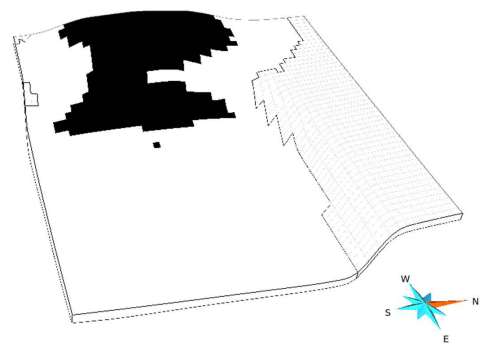



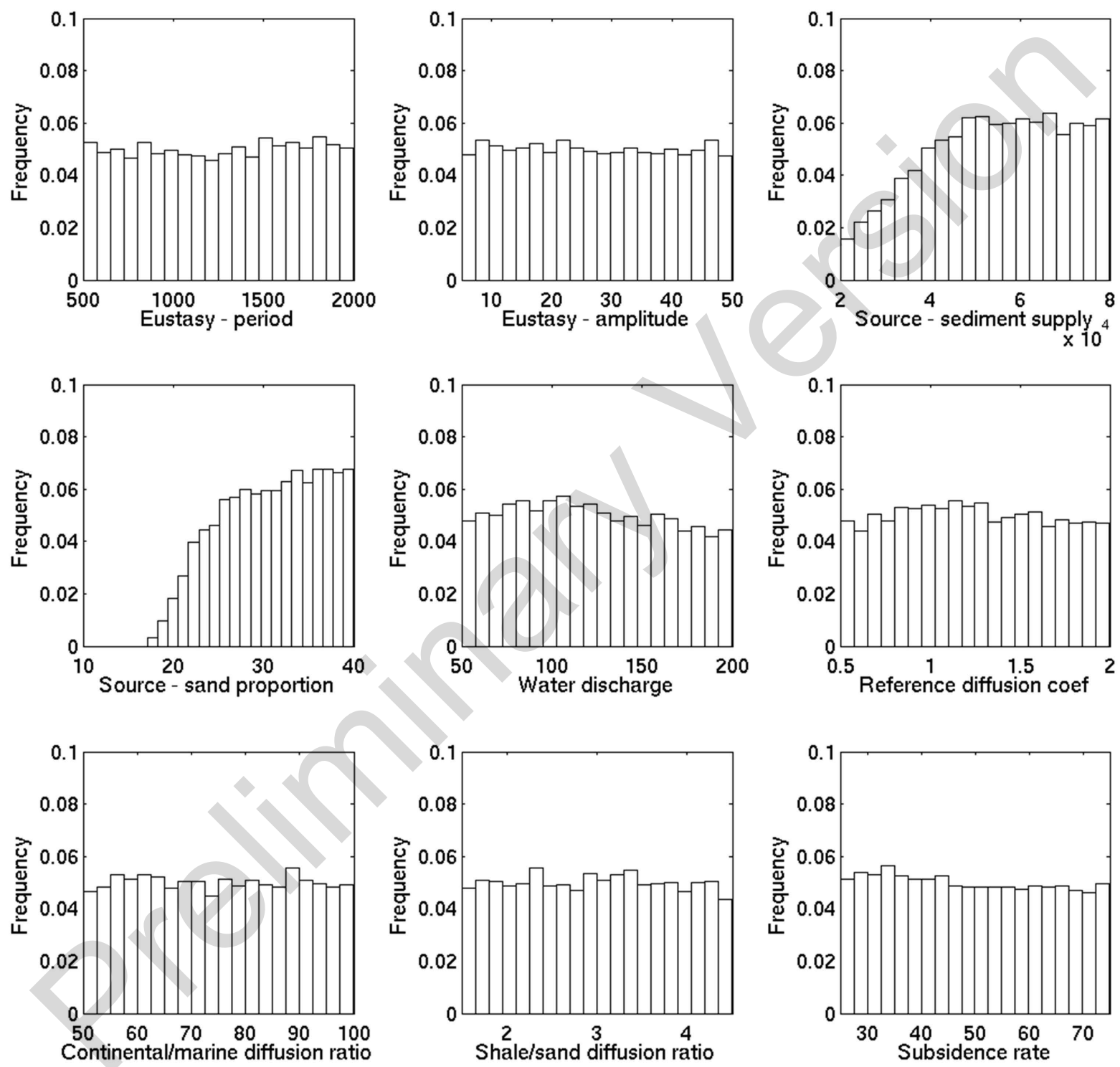
